\title{
Effect of aloe-emodin on the proliferation and apoptosis of human synovial MH7A cells; a comparison with methotrexate
}

\author{
MOTOKO HASHIGUCHI ${ }^{1}$, KAORI SUZUKI ${ }^{2}$, KAZUO KANEKO $^{1}$ and ISAO NAGAOKA ${ }^{2}$ \\ Departments of ${ }^{1}$ Medicine for Motor Organ and ${ }^{2}$ Host Defense and Biochemical Research, \\ Juntendo University Graduate School of Medicine, Tokyo 113-8421, Japan
}

Received May 20, 2016; Accepted February 21, 2017

DOI: $10.3892 / \mathrm{mmr} .2017 .6541$

\begin{abstract}
Rheumatoid arthritis (RA) is a chronic inflammatory disease characterized by synovial hyperplasia. Methotrexate (MTX), an antifolate derivative, is used for the treatment of RA, as it exerts antiproliferative efftects on lymphocytes and synovial cells. Aloe-emodin (AE) is a primary component of anthraquinones in Aloe vera and exerts antiproliferative and apoptotic effects on various tumor cells. In the present study, the effect of AE on the proliferation and apoptosis of MH7A human RA synovial cells was examined. In addition, the effect of AE was compared with that of the established RA therapeutic MTX. MH7A cells were incubated with 5, 10, 20 or $40 \mu \mathrm{M} \mathrm{AE}$, or $0.01,0.05,0.1$ or $1 \mu \mathrm{M}$ MTX, for 24,48 or $72 \mathrm{~h}$. Subsequently, total cell numbers were assessed using trypan blue staining and Cell Counting kit-8. Furthermore, MH7A cells incubated with AE or MTX for $48 \mathrm{~h}$ were evaluated for apoptosis following Annexin V/propidium iodide (PI) staining, and for cell cycle distribution following PI staining. The results indicated that $\geq 10 \mu \mathrm{M} \mathrm{AE}$ and $\geq 0.05 \mu \mathrm{M}$ MTX effectively decreased the numbers of viable MH7A cells. In addition, $40 \mu \mathrm{M} \mathrm{AE}$ and $1 \mu \mathrm{M}$ MTX induced apoptosis in MH7A cells. Cell cycle analysis revealed that $\geq 20 \mu \mathrm{M} \mathrm{AE}$ induced $\mathrm{G} 2 / \mathrm{M}$ phase arrest, whereas $\geq 0.1 \mu \mathrm{M}$ MTX induced $\mathrm{S}$ phase arrest. These observations suggested that AE treatment inhibited the growth of MH7A cells by arresting the cell cycle at a different checkpoint compared with MTX treatment. Thus, AE may be a potential therapeutic agent for the treatment of
\end{abstract}

Correspondence to: Dr Kaori Suzuki, Department of Host Defense and Biochemical Research, Juntendo University Graduate School of Medicine, 2-1-1 Hongo, Bunkyo-ku, Tokyo 113-8421, Japan E-mail: kasuzuki@juntendo.ac.jp

Abbreviations: RA, rheumatoid arthritis; AE, aloe-emodin; MTX, methotrexate; PI, propidium iodide; DMSO, dimethyl sulfoxide; ROS, reactive oxygen species

Key words: aloe-emodin, rheumatoid arthritis, synovial cells, methotrexate, proliferation, apoptosis, cell cycle
RA, and may be complimentary to MTX, based on its antiproliferative effect on synovial cells.

\section{Introduction}

Rheumatoid arthritis (RA) is a chronic autoimmune and inflammatory disease characterized by persistent synovitis; symptoms include joint pain, stiffness and swelling. In RA, chronic inflammation leads to synovial hyperplasia termed 'pannus', which erodes bone and cartilage, thereby destroying articular cartilage (1).

Synovial hyperplasia is caused by alterations in cell proliferation and cell death, involving increased proliferation and insufficient apoptosis of synovial cells (2-4). The proliferation of synovial cells is regulated by growth factors and cytokines produced in the local milieu $(5,6)$. The insufficient apoptosis of synovial cells is caused by the overexpression of transformation-associated proteins, such as tumor protein p53 $(7,8)$. Therefore, inhibiting proliferation and inducing apoptosis of synovial cells may constitute a promising strategy for the treatment of RA (3).

Methotrexate (MTX), an antifolate derivative, which inhibits DNA synthesis and induces apoptosis of tumor cells, is widely used as a therapeutic agent for malignant tumors. MTX is additionally utilized as a first-line RA treatment, as it exerts anti-inflammatory and antiproliferative effects on lymphocytes and synovial cells (9).

Aloe-emodin (AE; the chemical structure of which is presented in Fig. 1) is a primary bioactive component of Aloe vera, Aloe arborescens and certain Chinese herbs, including Rheum officinale. AE has been demonstrated to modulate various functions of host cells; AE exerts anti-inflammatory effects by inhibiting the activation of macrophages $(10,11)$ and antiproliferative effects on human tumor cells, including neuroblastoma, hepatoma, leukemia, tongue squamous cancer and colon cancer cells (12-17). In HL-60 human leukemia cells, AE exerts antitumor effects by inhibiting cell proliferation, and inducing apoptosis and cell cycle arrest (14). Based on these findings, the present study aimed to investigate whether AE may inhibit proliferation and induce apoptosis in synovial cells, which are important in the pathogenesis of RA. The effect of AE on cell growth, 
apoptosis and cell cycle distribution of synovial cells was evaluated using MH7A human RA synovial cells. In addition, the effect of AE was compared with the effect of MTX, an established first-line RA treatment.

\section{Materials and methods}

Reagents. AE and MTX were purchased from Sigma-Aldrich; Merck KGaA (Darmstadt, Germany). An 100 mM AE stock solution was prepared by dissolving AE in dimethyl sulfoxide (DMSO), and was stored at $-20^{\circ} \mathrm{C}$. The AE stock solution was further diluted to the indicated concentrations in culture media immediately prior to each experiment. The final concentrations of $\mathrm{AE}$ in the culture media were 5, 10, 20 and $40 \mu \mathrm{M}$. These concentrations were selected since $\mathrm{AE}$ at a concentration range of 6.25-50 $\mu \mathrm{M}$ has been reported to induce $\mathrm{G} 2 / \mathrm{M}$ cell cycle arrest and apoptosis through the activation of caspase- 6 in human colon cancer cells (16). MTX was dissolved in DMSO at $100 \mathrm{mM}$, and was further diluted in culture media. The final concentrations of MTX in the media were 0.01, 0.05, 0.1 and $1 \mu \mathrm{M}$.

Cell culture. MH7A human RA synovial fibroblast-like cells (18) were provided by the RIKEN BioResource Center (Tsukuba, Japan) through the National Bio-Resource Project of the Ministry of Education, Culture, Sports Science and Technology Japan, and maintained in RPMI-1640 medium (Invitrogen; Thermo Fisher Scientific, Inc., Waltham, MA, USA) supplemented with $10 \%$ fetal bovine serum (Nichirei Biosciences, Inc., Tokyo, Japan), $100 \mathrm{U} / \mathrm{ml}$ penicillin and $100 \mu \mathrm{g} / \mathrm{ml}$ streptomycin at $37^{\circ} \mathrm{C}$ in an atmosphere of $5 \% \mathrm{CO}_{2}$. Cells were passaged every 3-4 days.

Measurement of viable cells. MH7A cells $\left(5 \times 10^{4}\right.$ cells/well) were seeded into 12 -well plates and cultured for $24 \mathrm{~h}$. Cells were subsequently incubated with $5,10,20$ or $40 \mu \mathrm{M} \mathrm{AE}$, $0.01,0.05,0.1$ or $1 \mu \mathrm{M}$ MTX, or DMSO as a vehicle control ( $0.04 \%$ for AE and $0.001 \%$ for MTX), for 3 days. Following incubation, cells were harvested with trypsin/EDTA, stained with $0.25 \%$ trypan blue and counted using an automated cell counter (Thermo Fisher Scientific, Inc.).

Alternatively, MH7A cells $\left(1 \times 10^{4}\right.$ cells/well $)$ were seeded into 48-well plates and cultured for $24 \mathrm{~h}$. Cells were subsequently incubated with AE, MTX or DMSO, as aforementioned. Following incubation, live cells were evaluated using Cell Counting kit-8 (CCK-8; Dojindo Molecular Technologies, Inc., Kumamoto, Japan) according to the manufacturer's protocol. The absorbance of each well was measured at a wavelength of $450 \mathrm{~nm}$ using a microplate reader $\left(\mathrm{xMark}^{\mathrm{TM}}\right.$; Bio-Rad Laboratories, Inc., Hercules, CA, USA).

Analysis of cell death. MH7A cells $\left(2 \times 10^{5}\right.$ cells/well) were seeded into 6-well plates and cultured for $24 \mathrm{~h}$. Cells were subsequently incubated with AE, MTX or DMSO for 2 days. Following incubation, cells were harvested with trypsin/EDTA, and apoptosis was measured using an Annexin V-fluorescein isothiocyanate/propidium iodide (PI) assay kit (Medical \& Biological Laboratories Co., Ltd., Nagoya, Japan). Cells were analyzed for early and late apoptosis, and necrosis, using a flow cytometer (FACSCalibur; BD Biosciences, San Jose,

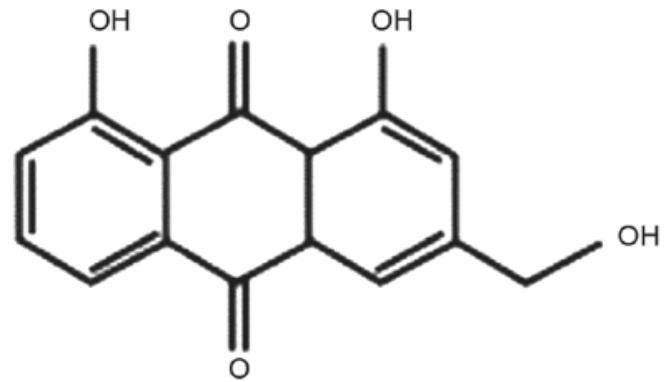

Figure 1. Chemical structure of aloe-emodin.

CA, USA) and the software BD CellQuest ${ }^{\mathrm{TM}}$ Pro version 6.0 (BD Biosciences).

Analysis of cell cycle phase distribution. MH7A cells $\left(2 \times 10^{5}\right.$ cells/well) were seeded into 6-well plates and cultured for $24 \mathrm{~h}$. Cells were subsequently incubated with AE, MTX or DMSO for 2 days. Following incubation, cells were harvested with trypsin/EDTA, fixed and permeabilized with $100 \%$ ethanol, stained with PI (Cell Cycle Phase Determination kit; Cayman Chemical Company, Ann Arbor, MI, USA) and analyzed by flow cytometry.

Statistical analysis. Data are presented as the mean \pm standard deviation. The statistical significance of the differences between groups was assessed using one-way analysis of variance followed by a post hoc Bonferroni test for multiple comparisons. Statistical analysis was performed using GraphPad Prism software version 5 (GraphPad Software, Inc., La Jolla, CA, USA). $\mathrm{P}<0.05$ was considered to indicate a statistically significant difference.

\section{Results}

Effect of AE and MTX treatment on the proliferation of $M H 7 A$ cells. To evaluate the effect of AE and MTX on the proliferation of synovial cells, MH7A cells were cultured for 3 days in the absence or presence of 5-40 $\mu \mathrm{M}$ AE or 0.01-1 $\mu \mathrm{M}$ MTX, and the number of viable cells was measured by trypan blue exclusion staining. As presented in Fig. 2, the total number of live MH7A cells increased $~ 8$-fold in 3 days of culture in the absence of AE and MTX. AE treatment inhibited the increase in cell number in a dose-dependent manner (Fig. 2A); however, this effect was not significant. MTX treatment significantly inhibited the increase in MH7A cell numbers at concentrations $\geq 0.05 \mu \mathrm{M}(\mathrm{P}<0.05$; Fig. 2B).

In addition, the effect of AE and MTX on MH7A cells was analyzed by CCK- 8 assay. CCK- 8 assay is based on reduction of tetrazolium salt by live and metabolically active cells, and is therefore utilized for the quantification of living cells in culture. As presented in Fig. 3, the number of viable MH7A cells increased $~ 6$-fold in 3 days in the absence of AE and MTX. When measured using the CCK-8 assay, 10-40 $\mu \mathrm{M}$ AE (Fig. 3A) and 0.05-1 $\mu \mathrm{M}$ MTX (Fig. 3B) significantly inhibited the increase in the number of live cells in a dose-dependent manner $(\mathrm{P}<0.05)$. These observations indicate that AE and MTX inhibit the proliferation of MH7A cells. 
A

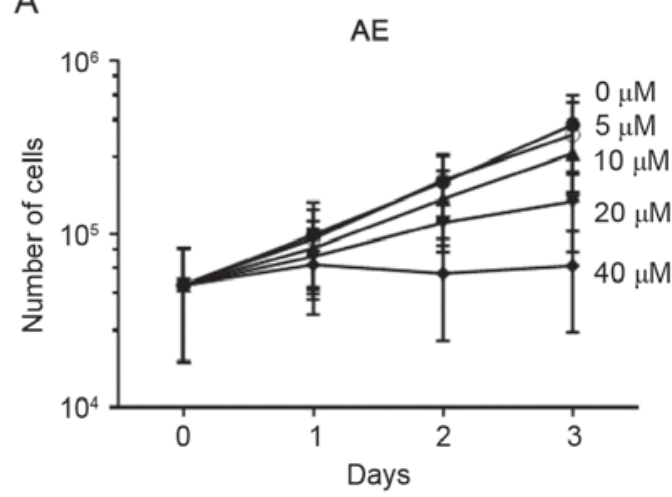

B

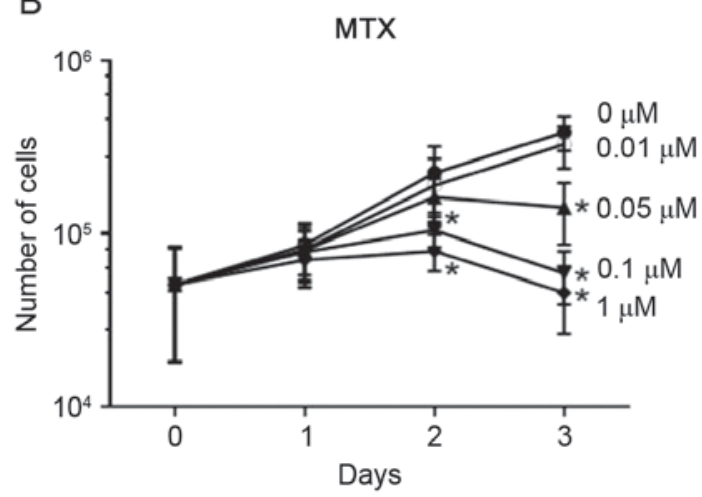

Figure 2. Evaluation of the effect of AE and MTX on MH7A cell proliferation by trypan blue staining. MH7A cells (5x104 cells/well) were seeded into 12 -well plates for $24 \mathrm{~h}$, and treated with (A) AE (5, 10,20 or $40 \mu \mathrm{M})$, or (B) MTX $(0.01,0.05,0.1$ or $1 \mu \mathrm{M})$ for 1,2 and 3 days. Cells treated with the vehicle dimethyl sulfoxide served as a control $(0 \mu \mathrm{M})$. The number of live cells was measured by trypan blue exclusion staining using an automated cell counter. Data are presented as the mean \pm standard deviation of 3 (AE) or 4 (MTX) independent experiments. " $\mathrm{P}<0.05$ vs. $0 \mu \mathrm{M}$. AE, aloe-emodin; MTX, methotrexate.

A

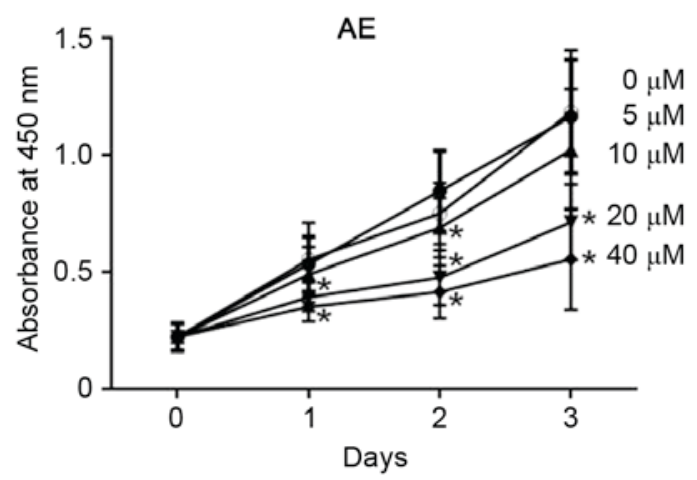

B



Figure 3. Evaluation of the effect of AE and MTX on MH7A cell proliferation by CCK-8 assay. MH7A cells (1x10 cells/well) were seeded into 48-well plates for $24 \mathrm{~h}$, and treated with (A) AE (5, 10, 20 or $40 \mu \mathrm{M})$, or (B) MTX $(0.01,0.05,0.1$ or $1 \mu \mathrm{M})$ for 1,2 and 3 days. Cells treated with the vehicle dimethyl sulfoxide served as a control $(0 \mu \mathrm{M})$. Live cell numbers were determined by CCK-8 assay. Data are presented as the mean \pm standard deviation of 3 (AE) or 4 (MTX) independent experiments. "P<0.05 vs. $0 \mu \mathrm{M}$. AE, aloe-emodin; MTX, methotrexate; CCK-8, Cell Counting kit-8.

Effect of AE and MTX treatment on MH7A cell death. The effect of AE and MTX treatment on MH7A cell death was examined. MH7A cells were incubated in the absence or presence of 5-40 $\mu \mathrm{M}$ AE or 0.01-1 $\mu \mathrm{M}$ MTX for 2 days, and apoptosis and necrosis were analyzed by Annexin V/PI staining (Fig. 4A). Flow cytometric analysis demonstrated that treatment with $40 \mu \mathrm{M} \mathrm{AE}$ significantly increased the percentage of Annexin $\mathrm{V}^{+} / \mathrm{PI}^{-}$(early apoptotic; $5.6 \pm 2.4$ vs. $1.2 \pm 0.4 \%$ ) and Annexin $\mathrm{V}^{+} / \mathrm{PI}^{+}$(late apoptotic; $6.2 \pm 1.0$ vs. $2.1 \pm 0.4 \%$ ) cells, compared with untreated MH7A cells $(\mathrm{P}<0.05$; Fig. 4B). This indicated that $\mathrm{AE}$ treatment induces early and late apoptosis in MH7A cells. Similarly, treatment with $1 \mu \mathrm{M}$ MTX increased the percentage of Annexin $\mathrm{V}^{+} / \mathrm{PI}^{-}(11.2 \pm 2.4$ vs. $1.8 \pm 0.4 \%)$ and Annexin $\mathrm{V}^{+} / \mathrm{PI}^{+}(8.6 \pm 2.6$ vs. $1.0 \pm 0.3 \%)$ cells, compared with untreated cells $(\mathrm{P}<0.05$; Fig. 4B). Concentrations $\leq 20 \mu \mathrm{M} \mathrm{AE}$ and $\leq 0.1 \mu \mathrm{M}$ MTX exhibited no effect on apoptosis (Fig. 4B). These observations indicated that only $40 \mu \mathrm{M}$ AE and $1 \mu \mathrm{M}$ MTX induced apoptotic cell death in MH7A cells. AE and MTX did not induce necrotic cell death (Annexin $\mathrm{V}^{-} / \mathrm{PI}^{+}$cells) in MH7A cells even at high concentrations evaluated in the present study (data not shown).

Effect of AE and MTX treatment on cell cycle phase distribution of MH7A cells. Cell proliferation is regulated by cell cycle progression. Thus, to clarify the underlying mechanism involved in the inhibitory action of AE or MTX on the proliferation of MH7A cells, the effect of AE and MTX on cell cycle phase distribution was examined. MH7A cells were cultured for 2 days in the absence or presence of 5-40 $\mu \mathrm{M}$ AE or $0.01-1 \mu \mathrm{M}$ MTX, and stained with PI to determine the DNA content of the cells (Fig. 5A). The results demonstrated that treatment with $40 \mu \mathrm{M}$ AE increased the percentage of cells in $\mathrm{G} 2 / \mathrm{M}$ phase and decreased the percentage of cells in G1 phase compared with untreated cells $(\mathrm{P}<0.05$; Fig. 5B), suggesting that $\mathrm{AE}$ induced $\mathrm{G} 2 / \mathrm{M}$ phase arrest in MH7A cells. Conversely, treatment with $1 \mu \mathrm{M}$ MTX significantly increased the percentage of cells in $\mathrm{S}$ phase and decreased the percentage of cells in $\mathrm{G} 2 / \mathrm{M}$ phases compared with untreated cells $(\mathrm{P}<0.05$; Fig. 5B). In addition, $1 \mu \mathrm{M}$ MTX slightly decreased the percentage of cells in G1 phase, although this effect was not significant. These observations suggested that MTX induced $\mathrm{S}$ phase arrest in MH7A cells. The effects of AE and MTX on the cell cycle were dose-dependent, with AE demonstrating significant effects at concentrations $\geq 20 \mu \mathrm{M}$ and MTX demonstrating significant effects at concentrations $\geq 0.05 \mu \mathrm{M}(\mathrm{P}<0.05$; Fig. 5B), compared with untreated cells. Notably, $20 \mu \mathrm{M} \mathrm{AE}$ and 0.05 and $0.1 \mu \mathrm{M}$ MTX significantly induced $\mathrm{G} 2 / \mathrm{M}$ and $\mathrm{S}$ 
A


B
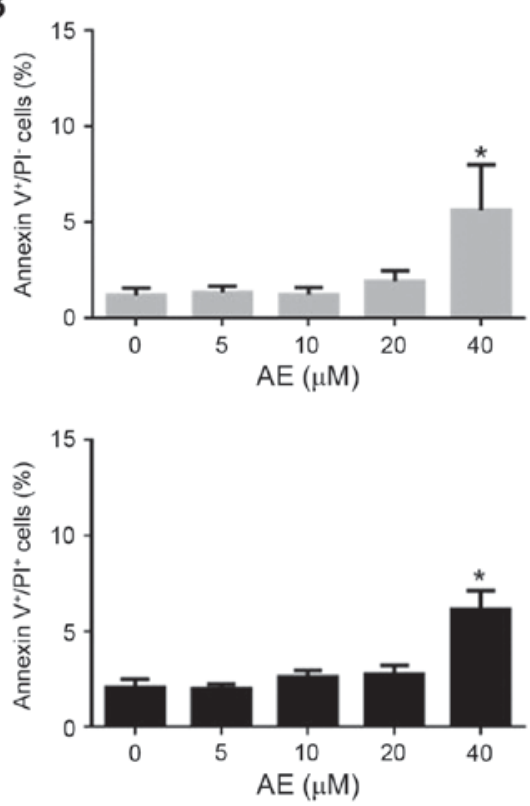
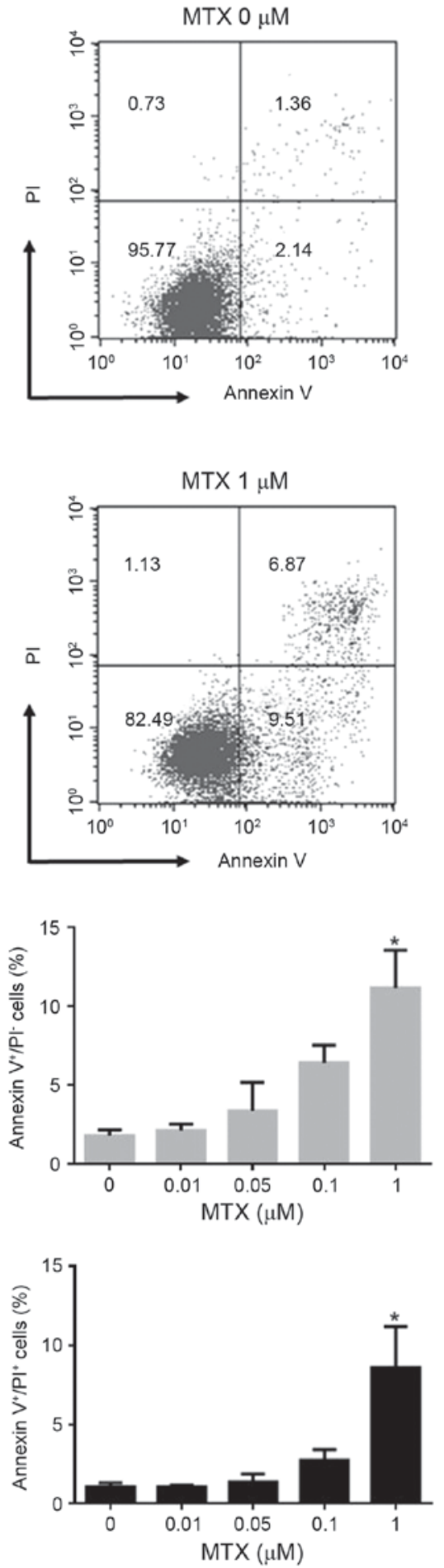

Figure 4. Evaluation of the effect of AE and MTX on cell death. MH7A cells (2x105 cells/well) were seeded into 6-well plates for $24 \mathrm{~h}$, and treated with AE $(5,10,20$ or $40 \mu \mathrm{M})$, or MTX $(0.01,0.05,0.1$ or $1 \mu \mathrm{M})$ for $48 \mathrm{~h}$. Cells treated with the vehicle dimethyl sulfoxide served as a control $(0 \mu \mathrm{M})$. Apoptosis was evaluated by Annexin V/PI staining followed by flow cytometric analysis. (A) Representative plots of control cells and cells treated with $40 \mu \mathrm{M}$ AE or $1 \mu \mathrm{M}$ MTX. (B) Quantification of the percentage of early $\left(A n n e x i n V^{+} / \mathrm{PI}^{-}\right)$and late $\left(A n n e x i n V^{+} / \mathrm{PI}^{+}\right)$apoptotic cells. Data are presented as the mean \pm standard deviation of 4 independent experiments. ${ }^{*} \mathrm{P}<0.05$ vs. $0 \mu \mathrm{M}$. AE, aloe-emodin; MTX, methotrexate; PI, propidium iodide.

phase arrest, respectively, whereas the same concentrations did not induce apoptotic cell death (Fig. 4).

\section{Discussion}

RA is a chronic inflammatory disease characterized by synovial hyperplasia, in which the proliferation of synovial cells and infiltrating macrophages and lymphocytes is increased, and apoptosis of these cells is decreased (3). MTX, an antifolate derivative, is presently a first-line RA treatment, as it exerts anti-inflammatory and antiproliferative effects on lymphocytes and synovial cells (19). However, the administration of MTX induces a variety of adverse effects, including potentially life-threatening hepatotoxicity, nephrotoxicity, 
A
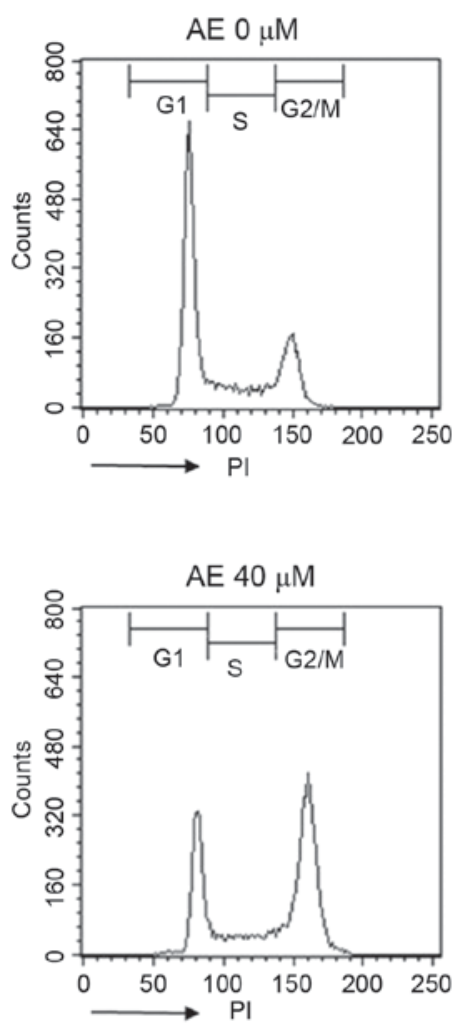

B




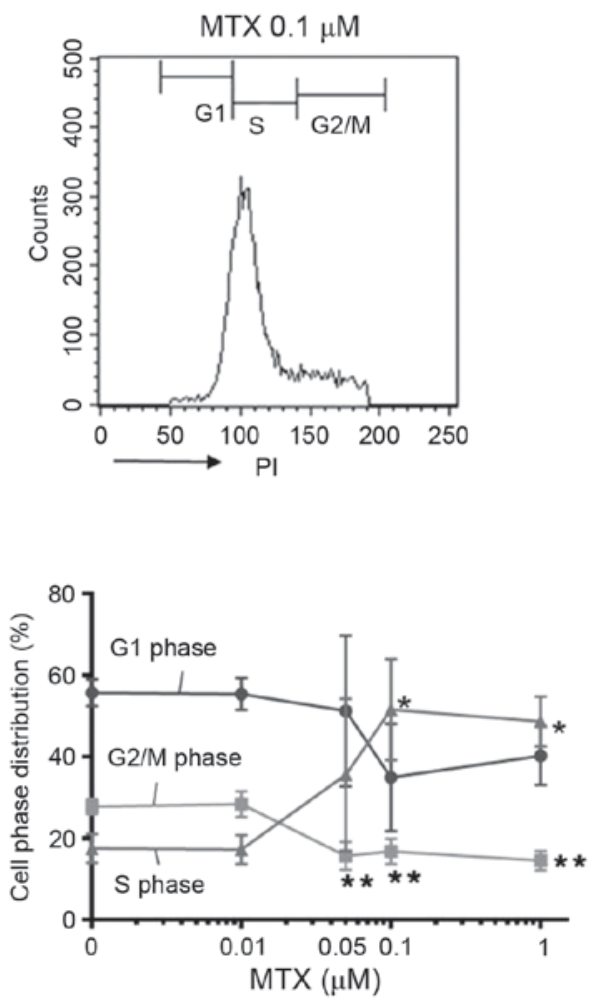

Figure 5. Evaluation of the effect of AE and MTX on cell cycle distribution. MH7A cells (2x10 5 cells/well) were seeded into 6-well plates for 24 h, and treated with $\operatorname{AE}(5,10,20$ or $40 \mu \mathrm{M})$, or MTX $(0.01,0.05,0.1$ or $1 \mu \mathrm{M})$ for $48 \mathrm{~h}$. Cells treated with the vehicle dimethyl sulfoxide served as a control $(0 \mu \mathrm{M})$. Cell cycle distribution was evaluated by PI staining followed by flow cytometric analysis. (A) Representative plots of control cells and cells treated with $40 \mu \mathrm{M}$ AE or $0.1 \mu \mathrm{M}$ MTX. (B) Quantification of the percentage of cells in the G1, G2/M and S phases. Data are presented as the mean \pm standard deviation of 4 independent experiments. ${ }^{*} \mathrm{P}<0.05$ and ${ }^{* *} \mathrm{P}<0.01$ vs. $0 \mu \mathrm{M}$. AE, aloe-emodin; MTX, methotrexate; PI, propidium iodide.

pulmonary damage and myelosuppression (20). Thus, RA patients are utilizing complementary and alternative medicine to treat RA symptoms $(21,22)$. AE, a bioactive component of Aloe, is hypothesized to act as an antitumor reagent (17), based on its suppressive action on the cell growth of various human tumor cells (12). In the present study, the effect of AE on the growth of synovial cells was examined, and it was revealed that $\geq 10 \mu \mathrm{M}$ AE significantly decreased the numbers of live MH7A cells, based on the CCK- 8 assay. A Trypan blue assay also revealed that $\mathrm{AE}$ decreased the viability of $\mathrm{MH7A}$ cells; however, the deviations of the data were high, and significance was not detected with regards to the Trypan blue assay.

Previous studies have demonstrated that AE induces apoptosis in various human tumor cell lines, including SJ-N-KP neuroblastoma, Hep G2 hepatoma and HL-60 leukemia cells (12-14). Thus, to elucidate whether AE induces the apoptosis of MH7A cells, apoptosis analysis was performed in AE-treated MH7A cells using AnnexinV/PI double staining followed by flow cytometry. The results indicated that following treatment for 2 days with $40 \mu \mathrm{M}$ AE, 5.6 and $6.2 \%$ of cells were early and late apoptotic, respectively, whereas the same concentration and duration of treatment inhibited MH7A cell proliferation by $69 \%$. In addition, AE did not induce apoptosis at concentrations $<40 \mu \mathrm{M}$, although AE significantly inhibited the proliferation of MH7A cells by $25 \%$ at $10 \mu \mathrm{M}$ and $59 \%$ at $20 \mu \mathrm{M}$, compared with untreated cells. Therefore, the inhibitory effects of AE on cell proliferation may not be fully explained by the induction of apoptosis.

Notably, AE has been reported to modulate the cell cycle, thereby suppressing the proliferation of cancer cells (14-16). 
Thus, to further clarify the underlying mechanism involved in the inhibitory effect of AE on the proliferation of MH7A cells, the effect of AE treatment on cell cycle progression was examined. The majority of cells analyzed in the untreated group were in G1 phase (in preparation for mitosis). AE treatment decreased the percentage of cells in G1 phase and increased the percentage of cells in $\mathrm{G} 2 / \mathrm{M}$ phase (prior to/in mitosis) in a dose-dependent manner compared with the untreated group, suggesting that $\mathrm{AE}$ induced $\mathrm{G} 2 / \mathrm{M}$ arrest in MH7A cells. These observations indicated that AE-treated MH7A cells may not complete mitosis. AE at a dose of $20 \mu \mathrm{M}$ induced $\mathrm{G} 2 / \mathrm{M}$ arrest, whereas the same dose was not sufficient to induce apoptotic cell death. Furthermore, $40 \mu \mathrm{M}$ AE induced cell cycle arrest in the G2/M phase by $23 \%$ among MH7A cells compared with untreated cells, whereas the same dose induced apoptosis in only $12 \%$ (5.6 and $6.2 \%$ of early and late apoptotic cells) of total cell population. These observations suggested that the G2/M phase arrest may be more important than the induction of apoptosis for the inhibition of cell proliferation by AE.

Consistent with the results of the present study, AE has been reported to induce $\mathrm{G} 2 / \mathrm{M}$ phase arrest in other cells, including HL-60 and WiDr colon adenocarcinoma cells $(14,16)$. In WiDr cells, the promoter activity and protein expression levels of cyclin B1, an essential factor for cell cycle progression from $\mathrm{G} 2$ to $\mathrm{M}$ phase, were strongly suppressed by AE treatment (16). Therefore, AE-mediated suppression of cyclin B1 may be involved in the inhibition of MH7A cell proliferation. By contrast, AE has been demonstrated to induce G1 phase arrest in Hep G2 human hepatoma cells (13), and S phase arrest in $\mathrm{FaDu}$ human pharyngeal squamous carcinoma, H1299 human lung cancer and MG-63 human osteosarcoma cells (23). These observations suggested that the cell cycle progression-associated target molecules of AE may differ in various cell types (17).

$\mathrm{AE}$ is a 1,8-dihydroxyanthraquinone compound, having an anthraquinone ring and two phenolic hydroxyl groups. Quinones are highly redox-active molecules that lead to the generation of reactive oxygen species (ROS). AE has been demonstrated to induce the loss of mitochondrial membrane potential and caspase-dependent apoptosis in SCC-4 human tongue squamous cancer cells, through increased ROS production (15). It is possible that ROS production may be involved in the AE-induced apoptosis of MH7A cells observed in the present study. However, MH7A cells are more resistant to AE compared with the cancer cells previously examined; $40 \mu \mathrm{M}$ AE induces $50 \%$ apoptosis in SCC-4 cells (15), and $40 \%$ apoptosis in $\mathrm{CH} 27$ human lung squamous carcinoma cells (24), whereas $40 \mu \mathrm{M}$ AE induced only $12 \%$ apoptosis in MH7A cells.

The effects of AE treatment were compared throughout the present study with the effects of 0.01-1 $\mu \mathrm{M}$ MTX. The concentrations of MTX were selected based on the concentrations detected in synovial fluids of RA patients treated with low-dose MTX $(\sim 1.3 \mu \mathrm{M})(25)$. The results indicated that $\geq 0.05 \mu \mathrm{M}$ MTX inhibited proliferation of MH7A cells, and $1 \mu \mathrm{M}$ MTX almost completely inhibited proliferation ( $90 \%$ in 3 days), compared with untreated cells. These observations are in agreement with previous reports that $2 \mu \mathrm{M}$ MTX inhibited cell growth by $\sim 80 \%$ in human synovial fibroblasts (6) and
$1 \mu \mathrm{M}$ MTX inhibited cell growth by $\sim 80 \%$ in adherent cells of rheumatic synovial tissue (26).

To understand the mechanism of MTX-induced inhibition of cell proliferation, the effect of MTX on MH7A cell death was examined in the present study. The results indicated that $1 \mu \mathrm{M}$ MTX treatment for 2 days induced early and late apoptosis in 11.2 and $8.6 \%$, respectively, of MH7A cells. By contrast, $1 \mu \mathrm{M}$ MTX inhibited the proliferation of MH7A cells by $\sim 80 \%$ at the same time point, suggesting that the induction of apoptosis only partially contributed to the inhibition of cell proliferation by MTX, similar to AE.

The effect of MTX on the cell cycle progression of MH7A cells was examined. In contrast to the action of $\mathrm{AE}$, MTX decreased the percentage of cells in G2/M phase and increased the percentage of cells in $\mathrm{S}$ phase in a dose-dependent manner, suggesting that MTX induces $S$ phase arrest in MH7A cells. Notably, MTX induced cell cycle arrest in the $\mathrm{S}$ phase by $34 \%$ in MH7A cells at $0.1 \mu \mathrm{M}$, a dose at which apoptotic cell death was not observed. A similar increase in $\mathrm{S}$ phase cells was observed following treatment with $1 \mu \mathrm{M}$, at which dose apoptotic cell death was induced in $20 \%(11.2$ and $8.6 \%$ of early and late apoptotic cells) of cells. These observations suggested that MTX-induced S phase arrest is more important than apoptosis in the MTX-mediated inhibition of proliferation.

As MTX is an antimetabolite that interferes with folate metabolism and DNA synthesis (6), explaining the induction of cell cycle arrest at the $\mathrm{S}$ phase. Apoptosis is additionally regulated by molecules involved in cell division and cell cycle progression (27). Thus, MTX-mediated S phase arrest may induce apoptosis in MH7A cells. In addition, AE-mediated G2/M phase arrest may induce apoptosis in MH7A cells.

In conclusion, the results of the present study revealed that AE, and MTX, treatment inhibited the proliferation of MH7A synovial cells. Furthermore, AE and MTX treatment induced apoptosis and cell cycle arrest (at G2/M and S phases, respectively) compared with untreated MH7A cells. For efficient therapeutic intervention in RA, it is essential to suppress proliferation and induce apoptosis of synovial and inflammatory cells in the RA joints $(2,3)$. Thus, the present results suggested that $\mathrm{AE}$, a natural component of Aloe, may be a safe and effective agent for the treatment of RA. Future studies are required to examine more fully the therapeutic potential of AE, including in vivo studies in animal models of RA.

\section{Acknowledgements}

The authors would like to thank Dr K. Miyazawa (Kissei Pharmaceutical Co., Ltd., Nagano, Japan) for establishing the MH7A cell line, and the researchers of the Division of Cell Biology in BioMedical Research Center and the Department of Host Defense and Biochemical Research, Juntendo University Graduate School of Medicine (Tokyo, Japan), for technical assistance and helpful discussion. This study was supported in part by a grant of The Strategic Research Foundation Grant-Aided Project for Private Universities from Ministry of Education, Culture, Sport, Science, and Technology, Japan (MEXT), 2014-2018 (S1411007). 


\section{References}

1. Müller-Ladner U, Pap T, Gay RE, Neidhart M and Gay S: Mechanisms of disease: The molecular and cellular basis of joint destruction in rheumatoid arthritis. Nat Clin Pract Rheumatol 1: 102-110, 2005

2. Nishioka K, Hasunuma T, Kato T, Sumida T and Kobata T: Apoptosis in rheumatoid arthritis: A novel pathway in the regulation of synovial tissue. Arthritis Rheum 41: 1-9, 1998.

3. Pope RM: Apoptosis as a therapeutic tool in rheumatoid arthritis. Nat Rev Immunol 2: 527-535, 2002

4. Bartok B and Firestein GS: Fibroblast-like synoviocytes: Key effector cells in rheumatoid arthritis. Immunol Rev 233: 233-255, 2010.

5. Arend WP and Dayer JM: Cytokines and cytokine inhibitors or antagonists in rheumatoid arthritis. Arthritis Rheum 33: 305-315, 1990.

6. Meyer FA, Yaron I, Mashiah V and Yaron M: Methotrexate inhibits proliferation but not interleukin-1 stimulated secretory activities of cultured human synovial fibroblasts. J Rheumatol 20 : 238-242, 1993

7. Firestein GS, Nguyen K, Aupperle KR, Yeo M, Boyle DL and Zvaifler NJ: Apoptosis in rheumatoid arthritis: p53 overexpression in rheumatoid arthritis synovium. Am J Pathol 149: 2143-2151, 1996.

8. Firestein GS, Echeverri F, Yeo M, Zvaifler NJ and Green DR: Somatic mutations in the p53 tumor suppressor gene in rheumatoid arthritis synovium. Proc Natl Acad Sci USA 94: 10895-10900, 1997.

9. Cutolo M, Sulli A, Pizzorni C, Seriolo B and Straub RH: Anti-inflammatory mechanisms of methotrexate in rheumatoid arthritis. Ann Rheum Dis 60: 729-735, 2001.

10. Park MY, Kwon HJ and Sung MK: Evaluation of aloin and aloe-emodin as anti-inflammatory agents in aloe by using murine macrophages. Biosci Biotechnol Biochem 73: 828-832, 2009.

11. Hu B, Zhang H, Meng X, Wang F and Wang P: Aloe-emodin from rhubarb (Rheum rhabarbarum) inhibits lipopolysaccharide-induced inflammatory responses in RAW264.7 macrophages. J Ethnopharmacol 153: 846-853, 2014.

12. Pecere T, Gazzola MV, Mucignat C, Parolin C, Vecchia FD, Cavaggioni A, Basso G, Diaspro A, Salvato B, Carli M and Palù G: Aloe-emodin is a new type of anticancer agent with selective activity against neuroectodermal tumors. Cancer Res 60: 2800-2804, 2000

13. Kuo PL, Lin TC and Lin CC: The antiproliferative activity of aloe-emodin is through p53-dependent and p21-dependent apoptotic pathway in human hepatoma cell lines. Life Sci 71: 1879-1892, 2002.
14. Chen HC, Hsieh WT, Chang WC and Chung JG: Aloe-emodin induced in vitro $\mathrm{G} 2 / \mathrm{M}$ arrest of cell cycle in human promyelocytic leukemia HL-60 cells. Food Chem Toxicol 42: 1251-1257, 2004.

15. Chiu TH, Lai WW, Hsia TC, Yang JS, Lai TY, Wu PP, Ma CY, Yeh CC, Ho CC, Lu HF, et al: Aloe-emodin induces cell death through S-phase arrest and caspase-dependent pathways in human tongue squamous cancer SCC-4 cells. Anticancer Res 29: 4503-4511, 2009.

16. Suboj P, Babykutty S, Srinivas P and Gopala S: Aloe emodin induces $\mathrm{G} 2 / \mathrm{M}$ cell cycle arrest and apoptosis via activation of caspase-6 in human colon cancer cells. Pharmacology 89: 91-98, 2012.

17. Chen R, Zhang J, Hu Y, Wang S, Chen M and Wang Y: Potential antineoplastic effects of aloe-emodin: A comprehensive review. Am J Chin Med 42: 275-288, 2014.

18. Miyazawa K, Mori A and Okudaira H: Establishment and characterization of a novel human rheumatoid fibroblast-like synoviocyte line, MH7A, immortalized with SV40 T antigen. J Biochem 124: 1153-1162, 1998

19. Cronstein BN: Low-dose methotrexate: A mainstay in the treatment of rheumatoid arthritis. Pharmacol Rev 57: 163-172, 2005.

20. Kremer JM: Major side effects of low-dose methotrexate. In: UpToDate. Ravinder NM (ed). UpToDate, Inc., Waltham, MA, 2014.

21. Herman CJ, Allen P, Hunt WC, Prasad A and Brady TJ: Use of complementary therapies among primary care clinic patients with arthritis. Prev Chronic Dis 1: A12, 2004.

22. Ernst E: Herbal medicine in the treatment of rheumatic diseases Rheum Dis Clin North Am 37: 95-102, 2011.

23. Lin ML, Lu YC, Su HL, Lin HT, Lee CC, Kang SE, Lai TC, Chung JG and Chen SS: Destabilization of CARP mRNAs by aloe-emodin contributes to caspase-8-mediated p53-independent apoptosis of human carcinoma cells. J Cell Biochem 112: 1176-1191, 2011.

24. Lee HZ, Hsu SL, Liu MC and Wu CH: Effects and mechanisms of aloe-emodin on cell death in human lung squamous cell carcinoma. Eur J Pharmacol 431: 287-295, 2001.

25. Tishler M, Caspi D, Graff E, Segal R, Peretz H and Yaron M: Synovial and serum levels of methotrexate during methotrexate therapy of rheumatoid arthritis. Br J Rheumatol 28: 422-423, 1989.

26. Nakazawa F, Matsuno H, Yudoh K, Katayama R, Sawai T, Uzuki M and Kimura T: Methotrexate inhibits rheumatoid synovitis by inducing apoptosis. J Rheumatol 28: 1800-1808, 2001.

27. Pucci B, Kasten M and Giordano A: Cell cycle and apoptosis. Neoplasia 2: 291-299, 2000 